This item was submitted to Loughborough's Research Repository by the author.

Items in Figshare are protected by copyright, with all rights reserved, unless otherwise indicated.

\title{
Estimating efficiency spillovers with state level evidence for manufacturing in the US
}

PLEASE CITE THE PUBLISHED VERSION

http://dx.doi.org/10.1016/j.econlet.2014.01.037

PUBLISHER

(c) Elsevier

VERSION

AM (Accepted Manuscript)

\section{PUBLISHER STATEMENT}

This work is made available according to the conditions of the Creative Commons Attribution-NonCommercialNoDerivatives 4.0 International (CC BY-NC-ND 4.0) licence. Full details of this licence are available at: https://creativecommons.org/licenses/by-nc-nd/4.0/

\section{LICENCE}

CC BY-NC-ND 4.0

\section{REPOSITORY RECORD}

Glass, Anthony J., Karligash Kenjegalieva, and Robin C. Sickles. 2019. "Estimating Efficiency Spillovers with State Level Evidence for Manufacturing in the US". figshare. https://hdl.handle.net/2134/17626. 


\title{
Estimating Efficiency Spillovers with State Level Evidence for Manufacturing in the U.S.
}

\author{
Anthony Glass $^{\mathrm{a}, *}$, Karligash Kenjegalieva ${ }^{\mathrm{a}}$, Robin C. Sickles ${ }^{\mathrm{b}}$ \\ ${ }^{a}$ School of Business and Economics, Loughborough University, Leics, LE11 3TU, UK \\ ${ }^{b}$ Department of Economics, Rice University, Houston, U.S., and School of Business and \\ Economics, Loughborough University, Leics, LE11 3TU, UK
}

\begin{abstract}
7 Abstract
Unit specific effects are often used to estimate non-spatial efficiency. We extend such estimators to the case where there is spatial autoregressive dependence and introduce the concept of spillover efficiency. Intuitively, we present an approach to benchmark how successful units are at exporting and importing productive performance to and from other units.

JEL Classification: C23; C51; D24

Keywords: Spatial Autoregression, Frontier Modeling, Panel Data, Efficiency Spillovers
\end{abstract}

\footnotetext{
*Corresponding author- E-mail: A.J.Glass@lboro.ac.uk; Tel: +44 1509 222704; Fax: +441509223910.
} 


\section{Introduction}

The Schmidt \& Sickles (1984) (SS) time-invariant efficiency estimator benchmarks the relative performance of the cross-sectional units using the fixed or random effects. The SS estimator was extended to the case of timevariant efficiency by Cornwell et al. (1990) (CSS). We extend the non-spatial CSS estimator to the case where there is spatial autoregressive dependence which involves estimating direct (own), indirect (spillover) and total (direct plus indirect) efficiency. We provide a demonstration of our estimator using a cost frontier model for state manufacturing in the U.S.. In the context of our application, cost efficiency spillovers can be interpreted as benchmarking how successful states are at exporting and importing productive performance to and from other states. For example, firms in different states may effectively export and import efficiency to and from one another via competition.

\section{Deterministic Spatial Autoregressive Cost Frontier Model}

A deterministic spatial autoregressive cost frontier model for panel data is given in equation (1). We do not discuss spatial panel data models in detail here but for comprehensive and up-to-date surveys see Baltagi (2011, 2013).

$$
\begin{gathered}
C_{i t}=\kappa+\alpha_{i}+\tau_{t}+T L(h, q, t)_{i t}+\lambda \sum_{j=1}^{N} w_{i j} C_{j t}+z_{i t} \phi+\varepsilon_{i t}, \\
i=1, \ldots, N ; t=1, \ldots, T .
\end{gathered}
$$

$N$ is a cross-section of units; $T$ is the fixed time dimension; $C_{i t}$ is the logged normalized cost of the $i$ th unit; $\alpha_{i}$ is a fixed effect; $\tau_{t}$ is a time period effect; $T L(h, q, t)_{i t}$ represents the technology as the translog approximation of the $\log$ of the cost function, where $h$ is a vector of logged normalized input prices, $q$ is a vector of logged outputs and $t$ is a time trend; $\lambda$ is the spatial autoregressive parameter; $w_{i j}$ is an element of the spatial weights matrix, $W ; z_{i t}$ is a vector of exogenous characteristics and $\phi$ is the associated vector of parameters; $\varepsilon_{i t}$ is an i.i.d. disturbance for $i$ and $t$ with zero mean and variance $\sigma^{2}$.

$W$ is a $(N \times N)$ matrix of known positive constants which describes the spatial arrangement of the cross-sectional units and also the strength of the 
spatial interaction between the units. All the elements on the main diagonal of $W$ are set to zero. $\lambda$ is assumed to lie in the interval $\left(1 / r_{\min }, 1\right)$, where $r_{\min }$ is the most negative real characteristic root of $W$ and because $W$ is row-normalized 1 is the largest real characteristic root of $W$.

Equation (1) is estimated using maximum likelihood where the log likelihood function is:

$$
\begin{array}{r}
\log L=\frac{-N T}{2} \log \left(2 \pi \sigma^{2}\right)+T \log |I-\lambda W|-\frac{1}{2 \sigma^{2}} \sum_{i=1}^{N} \sum_{t=1}^{T}\left(C_{i t}-\kappa-\right. \\
\left.\alpha_{i}-\tau_{t}-T L(h, q, t)_{i t}-\sum_{j=1}^{N} w_{i j} C_{j t}-z_{i t} \phi\right) .
\end{array}
$$

We ensure that $\lambda$ lies in its parameter space, account for the endogeneity of the spatial autoregressive variable and the fact that $\varepsilon_{t}$ is not observed by including the scaled logged determinant of the Jacobian transformation of $\varepsilon_{t}$ to $C_{t}$ (i.e. $T \log |I-\lambda W|$ ) in the $\log$-likelihood function. We estimate equation (1) by demeaning in the space dimension to circumvent the incidental parameter problem. Lee \& Yu (2010), however, show that this leads to a biased estimate of $\sigma^{2}$ when $N$ is large and $T$ is fixed, which we denote $\sigma_{B}^{2}$, where the bias is of the type identified in Neyman \& Scott (1948). Following Lee \& Yu (2010) we correct for this bias by replacing $\sigma_{B}^{2}$ with the bias corrected estimate of $\sigma^{2}, \sigma_{B C}^{2}=T \sigma_{B}^{2} /(T-1)$.

\section{Marginal Effects and Direct, Indirect and Total Efficiencies}

We can rewrite equation (1) as follows where the $i$ subscripts are dropped to denote successive stacking of cross-sections.

$$
\begin{aligned}
C_{t}= & (I-\lambda W)^{-1} \kappa \iota+(I-\lambda W)^{-1} \alpha+(I-\lambda W)^{-1} \tau_{t} \iota+ \\
& (I-\lambda W)^{-1} \Gamma_{t} \beta+(I-\lambda W)^{-1} z_{t} \phi+(I-\lambda W)^{-1} \varepsilon_{t},
\end{aligned}
$$

where $\iota$ is an $(N \times 1)$ vector of ones; $\alpha$ is the $(N \times 1)$ vector of fixed effects; $\Gamma_{t}$ is an $(N \times K)$ matrix of stacked observations for $T L(h, q, t)_{t}$; and $\beta$ is a vector of translog parameters. LeSage \& Pace (2009) demonstrate that the coefficients on the explanatory variables in a model with spatial autoregressive dependence cannot be interpreted as elasticities. LeSage \& Pace (2009) 
therefore propose the following approach to calculate direct, indirect and total marginal effects which we present in the context of the $k t h$ component of the translog function.

The matrix of direct and indirect elasticities for each unit for the kth component of the translog function are given by:

$$
(I-\lambda W)^{-1}\left[\begin{array}{cccc}
\beta_{k} & 0 & \cdot & 0 \\
0 & \beta_{k} & \cdot & \cdot \\
\cdot & \cdot & \cdot & \cdot \\
0 & 0 & \cdot & \beta_{k}
\end{array}\right]
$$

Since the product of matrices in equation (4) yields different direct and indirect elasticities for each unit, to facilitate interpretation LeSage \& Pace (2009) suggest reporting a mean direct elasticity (average of the diagonal elements in equation (4)) and a mean aggregate indirect elasticity (average row sum of the non-diagonal elements in equation (4)). The mean direct effect is the mean effect on a unit's dependent variable following a change in one of its independent variables. The mean aggregate indirect effect is the mean effect on the dependent variable of one unit following a change in one of the independent variables in all the other units. The mean total effect is the sum of the mean direct and mean aggregate indirect effects. We calculate the $t$-statistics for the mean effects using the delta method.

Unit specific effects from a deterministic spatial frontier model can be used to calculate time-invariant and time-variant efficiency by applying the non-spatial SS and CSS estimators, respectively, where the efficiencies are comparable to those from a non-spatial deterministic frontier model using the same procedure (see Druska \& Horrace (2004) and Glass et al. (2013)). We extend the CSS methodology to the spatial autoregressive case and thus estimate direct, indirect and total efficiencies, which involves recognizing from equation (3) that $(I-\lambda W)^{-1} \alpha=\alpha^{T o t}$, where $\alpha^{T o t}$ is the $(N \times 1)$ vector of total fixed effects. Equivalently using column vector notation:

$$
(I-\lambda W)^{-1}\left(\begin{array}{c}
\alpha_{1} \\
\alpha_{2} \\
\cdot \\
\cdot \\
\alpha_{N}
\end{array}\right)=\left(\begin{array}{cccccccc}
\alpha_{11}^{D i r} & + & \alpha_{12}^{I n d} & + & \cdot & \cdot & + & \alpha_{1 N}^{I n d} \\
\alpha_{21}^{I n d} & + & \alpha_{22}^{D i r} & + & \cdot & \cdot & + & \alpha_{2 N}^{I n d} \\
\cdot & + & \cdot & + & \cdot & \cdot & + & \cdot \\
\cdot & + & \cdot & + & \cdot & \cdot & + & \cdot \\
\alpha_{N 1}^{I n d} & + & \alpha_{N 2}^{I n d} & + & \cdot & \cdot & + & \alpha_{N N}^{D i r}
\end{array}\right)=\left(\begin{array}{c}
\alpha_{1}^{T o t} \\
\alpha_{2}^{T o t} \\
\cdot \\
\cdot \\
\alpha_{N}^{T o t}
\end{array}\right)
$$

where $\alpha_{i j}^{\text {Dir }}$ (i.e. where $i=j$ ) and $\alpha_{i j}^{I n d}$ (i.e. where $i \neq j$ ) are direct and 


$$
C I E_{i t}^{T o t}=\left[\min _{i}{ }_{C E_{i t}^{T o t}}\left(\delta_{i t}^{D i r}\right)-\delta_{i t}^{D i r}\right]+\left[\min _{i} E_{i t}^{T o t}\left(\delta_{i t}^{A g g I n d}\right)-\delta_{i t}^{A g g I n d}\right],
$$


from which $S C I E_{i t}^{\text {Dir }}$ is:

$$
S C I E_{i t}^{D i r}=\left[\min _{i}\left(E_{i t}^{T o t}\left(\delta_{i t}^{D i r}\right)-\delta_{i t}^{D i r}\right] / C I E_{i t}^{T o t} .\right.
$$

$S C I E_{i t}^{\text {AggInd }}$ can be calculated in a similar manner.

\section{Application}

\subsection{Data}

Our data is for the period 1997-2008 for the contiguous states in the U.S.. We obtained all data from the Annual Survey of Manufactures (ASM) unless otherwise stated and all monetary variables are expressed in 1997 prices using the CPI. The measure of output is value added $(q)$, and the three input prices are the price of capital $\left(h_{1}\right)$, average annual wage of a production worker $\left(h_{2}\right)$ and the price of energy $\left(h_{3}\right)$, where all three input prices and $C$ are normalized by the average annual wage of a non-production worker. The data for $C$ is calculated by summing the annual wage bills for production and nonproduction workers, expenditure on new and used capital, and expenditure on fuels and electricity. The ASM only contains manufacturing expenditure on fuels and electricity for the U.S. so this expenditure was allocated to the states using annual shares of U.S. industrial sector energy expenditure, where the state shares were calculated using data from the U.S. Energy Administration. The data for $h_{3}$ is from the U.S. Energy Administration and is the price paid by the industrial sector per million Btu.

Following Morrison \& Schwartz (1996) we assume a harmonized capital market and the price of capital is approximated by $T X_{t} P K_{t}\left(r_{t}+\gamma\right)$. TX is the corporate tax rate which we obtain for the U.S. from the OECD tax database; $P K_{t}$ is the PPI for finished capital equipment; $r_{t}$ is the long-term lending rate for the manufacturing sector approximated by Moody's Baa corporate bond yield; and $\gamma$ is the depreciation rate, which following Hall (2005) we assume is $10 \%$. The price of capital will not be correlated with the fixed effects because the price of capital varies over time. The price of capital, however, does not vary in the cross section and was therefore found to be correlated with the time period effects so the time period effects were omitted.

We also include a number of $z$-variables which shift the cost frontier technology. To capture the effect of differences in tax conditions across states 
we include the ratio of personal current tax payments to personal income $\left(z_{1}\right)$. Since the density of economic activity in a state is not meaningful because parcels of land are often not productive, we follow Ciccone \& Hall (1996) and control for agglomeration effects by including average county employment density within a state $\left(z_{2}\right)$. We take account of urban roadway congestion by including urban national highway length shares with a volume-service flow (VSF) ratio: < 0.21; 0.21-0.40; 0.71-0.79; 0.80-0.95; and >0.95 $\left(z_{3^{-}}\right.$ $z_{7}$, respectively, where we omit the $0.41-0.70$ share). A VSF ratio $>0.80$ indicates that congestion has set in. To capture the effect of the sectoral composition of state output we include as shares of state GDP, agriculture, forestry and fishing GDP $\left(z_{8}\right)$, service sector GDP $\left(z_{9}\right)$ and government GDP $\left(z_{10}\right)$, all of which we interact with $q .^{1}$

Two states with small manufacturing sectors are highly efficient outliers (Rhode Island and Delaware) and were omitted. We use two specifications of $W$. The first is a contiguity matrix, $W_{1}$. The second is a matrix weighted by inverse distance between all state centroids denoted $W_{2}$. $W_{2}$ therefore resembles the variable which measures the geographical distance between trading partners in gravity models. With the exception of the data for $z_{1}$ and $z_{3}-z_{10}$, all the data is logged and mean adjusted. Consequently, the first order coefficients on the time trend, output and input prices can be interpreted as elasticities because at the sample mean the quadratic and cross terms in the translog function are zero.

\subsection{Estimation Results}

In Table 1 we present the non-spatial Within model (denoted no spatial dependence, No SD) as well as the marginal effects for the $W_{1}$ and $W_{2}$ models. We get an indication of whether the $z$-variables are endogenous by using the non-spatial Within model and the Hausman-Taylor with fixed effects model to perform a Hausman-Wu test. The test accepts the null of no endogeneity bias at the $10 \%$ level. For both spatial models an LR test rejects the null that the fixed effects are not jointly significant at the $0.1 \%$ level.

\footnotetext{
${ }^{1}$ The tax and income data to calculate $z_{1}$, the county employment data to calculate $z_{2}$ and the industry level state GDP data to calculate $z_{8}$ and $z_{10}$ was obtained from the Regional Economic Accounts. $z_{3}-z_{7}$ were calculated using data from Highway Statistics. $z_{9}$ is calculated using data from the Regional Economic Accounts for the industries which constitute the service sector in the Annual and Quarterly Services Report.
} 
Table 1: Fitted deterministic cost frontier models

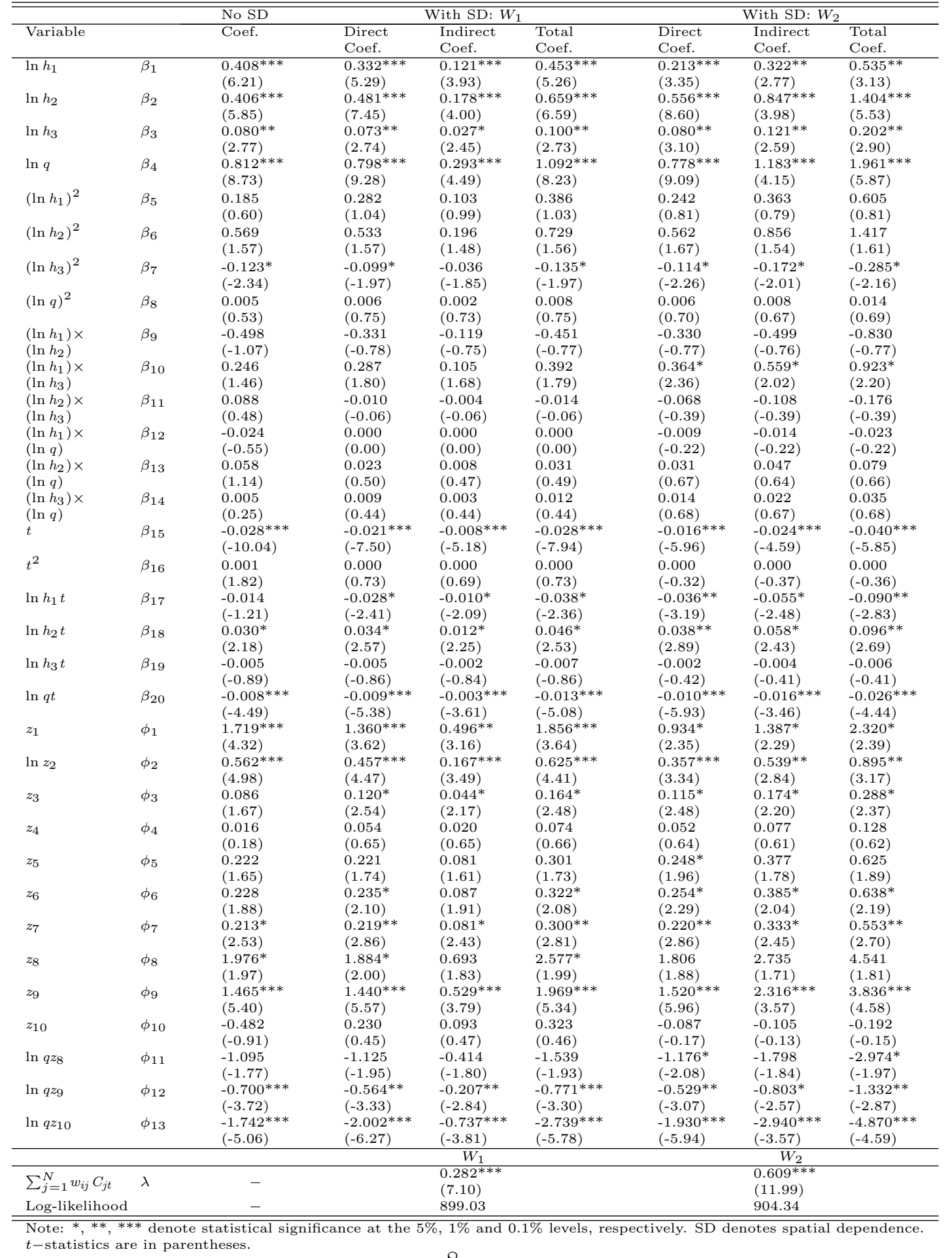


The estimates of $\lambda$ are 0.28 from the $W_{1}$ model and 0.61 from the $W_{2}$ model, both of which are significant at the $0.1 \%$ level. This indicates that there is a lot more spatial dependence when we allow spatial interaction between all states $\left(W_{2}\right)$ compared to when spatial interaction is limited to contiguous states $\left(W_{1}\right)$. This is almost certainly because with $W_{2}$ there are more states from which there can be spillovers than there are with $W_{1}$. In both models the direct $q, h_{1}, h_{2}$ and $h_{3}$ parameters are significant at the $0.1 \%$ level. These parameters are also positive which indicates that the monotonicity of the cost function is satisfied at the sample mean. The estimates of direct returns to scale $\left(1 / \beta_{4}\right)$ from both spatial models are sensible thereby providing support for the model specifications (1.25 from the $W_{1}$ model and 1.29 from the $W_{2}$ model indicating increasing returns in both cases). For both spatial models, it is clear that the largest indirect input price or output parameter relates to $h_{2}$. This indicates that there are larger production wage spillovers than there are output, capital price or energy price spillovers.

We find that the direct $z_{2}, z_{6}$ and $z_{7}$ parameters are positive and significant at the $5 \%$ level or lower in the spatial models. The implication is that state manufacturing cost will be higher in more urbanized states where employment density and urban roadway congestion are higher. The direct $z_{3}$ parameter suggests that state manufacturing cost is higher for the least urbanized states, where low traffic levels on urban highways is a more frequently observed phenomenon.

\subsection{Direct, Aggregate Indirect and Total Efficiencies}

Efficiencies from the spatial models which are calculated using equations (6)-(8) are denoted by $C E_{A}$ in Table 2 . To calculate the direct and aggregate indirect inefficiency shares, which are denoted by SCIE in Table 2, we use direct, aggregate indirect and total efficiencies which are based on equation (9) and are denoted by $C E_{B}$ in Table 2 . The sample average $C E_{A}$ from the non-spatial model and the sample average direct $C E_{A}$ from the $W_{1}$ model are in both cases 0.28 , which rises to 0.34 for the $W_{2}$ model. The average aggregate indirect (total) $C E_{A}$ is $0.69(0.25)$ for the $W_{1}$ model and 0.76 (0.32) for the $W_{2}$ model. This suggests that direct efficiency is the principal component of total efficiency. Moreover, average total $C E_{A}$ from the $W_{1}$ and $W_{2}$ models is below average direct $C E_{A}$ because there is a sufficient amount of aggregate indirect inefficiency, although as we will see this is not always the case for individual states. We can see from Figure 1 that annual aggregate indirect $C E_{A}$ is considerably greater than annual direct $C E_{A}$ over 
(a) SD W1

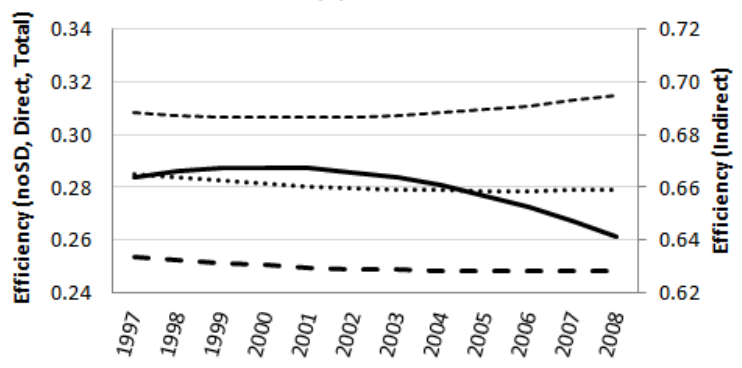

- no SD $\cdots \cdots$ Direct SD W1 - - Total SD W1 ----- Indirect SD W1 (b) SD W2

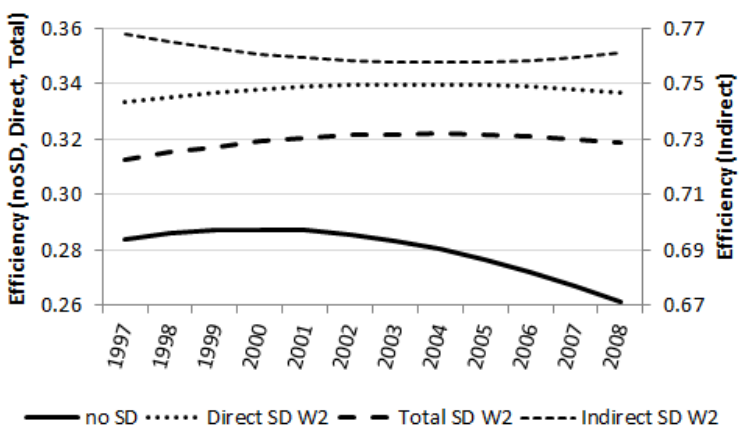

Figure 1: Average efficiency scores

the entire sample for both spatial models. We also observe that annual aggregate indirect $C E_{A}$ for the $W_{2}$ model is always greater than that from the $W_{1}$ model.

We can see from Table 2 that we observe states where total $C E_{A}$ is in between direct and aggregate indirect $C E_{A}$ because there is an insufficient amount of aggregate indirect inefficiency e.g. New York for $W_{1}$ and $W_{2}$. Also, Table 2 indicates that, in general, the average direct and average aggregate indirect $C E_{A}$ rankings are high for several states in the Northeastern region or just outside for both spatial models. The two states with the largest average real GDP and average state manufacturing real GDP over the study period (California and Texas) have the lowest average direct $C E_{A}$. In terms of average aggregate indirect $C E_{A}$, California and Texas fair much better. A comparison of average direct, average aggregate indirect and average total $C E_{A}$ for California and Texas indicates that average direct $C E_{A}$ is the reason for their low average total $C E_{A}$.

Some of the estimates of average aggregate indirect $C E_{B}$ are greater than 1 and when this is the case average aggregate indirect $S C I E$ is negative. This is because New Jersey and Maryland are the best performing states in each period for the calculation of total $C E_{B}$ for $W_{1}$ and $W_{2}$, respectively, but this is not the case for the calculation of aggregate indirect $C E_{B}$. To illustrate, consider the average estimates of direct and aggregate indirect $S C I E$ of 1.40 and -0.40 for Vermont from the $W_{2}$ model. These estimates indicate that Vermont operates below the direct reference level but above the aggregate indirect reference level. We can therefore conclude that Vermont's relative total inefficiency is all due to its relative direct inefficiency as its aggregate indirect efficiency is higher than Maryland's. 
Table 2: Selected average cost efficiencies and inefficiency shares

\begin{tabular}{|c|c|c|c|c|c|c|c|c|}
\hline \multirow[t]{2}{*}{ State } & & \multirow[t]{2}{*}{ No SD } & \multicolumn{3}{|c|}{ With SD: $W_{1}$} & \multicolumn{3}{|c|}{ With SD: $W_{2}$} \\
\hline & & & Direct & Agg Indirect & Total & Direct & Agg Indirect & Total \\
\hline \multirow[t]{3}{*}{ New York } & $C E_{A}$ & $1.00(1)$ & $0.75(4)$ & $0.91(4)$ & $0.82(3)$ & $0.63(5)$ & $0.99(2)$ & $0.74(5)$ \\
\hline & $C E_{B}$ & & $0.75(4)$ & $1.09(4)$ & $0.82(3)$ & $0.63(5)$ & $1.16(2)$ & $0.74(5)$ \\
\hline & $S C I E$ & & 1.45 & -0.45 & & 1.51 & -0.51 & \\
\hline \multirow[t]{3}{*}{ Massachusetts } & $C E_{A}$ & $0.97(2)$ & $0.68(5)$ & $0.93(3)$ & $0.76(5)$ & $0.67(4)$ & $0.97(5)$ & $0.77(4)$ \\
\hline & $C E_{B}$ & & $0.68(5)$ & $1.11(3)$ & $0.76(5)$ & $0.67(4)$ & $1.14(5)$ & $0.77(4)$ \\
\hline & $S C I E$ & & 1.39 & -0.39 & & 1.51 & -0.51 & \\
\hline \multirow[t]{3}{*}{ Maryland } & $C E_{A}$ & $0.94(3)$ & $0.86(2)$ & $0.75(9)$ & $0.78(4)$ & $1.00(1)$ & $0.85(11)$ & $1.00(1)$ \\
\hline & $C E_{B}$ & & $0.86(2)$ & $0.90(9)$ & $0.78(4)$ & $1.00(1)$ & $1.00(11)$ & $1.00(1)$ \\
\hline & $S C I E$ & & 0.59 & 0.41 & & $\mathrm{~N} / \mathrm{A}$ & $\mathrm{N} / \mathrm{A}$ & \\
\hline \multirow[t]{3}{*}{ New Jersey } & $C E_{A}$ & $0.93(4)$ & $1.00(1)$ & $0.84(8)$ & $1.00(1)$ & $0.78(3)$ & $0.91(8)$ & $0.84(3)$ \\
\hline & $C E_{B}$ & & $1.00(1)$ & $1.00(8)$ & $1.00(1)$ & $0.78(3)$ & $1.07(8)$ & $0.84(3)$ \\
\hline & $S C I E$ & & $\mathrm{~N} / \mathrm{A}$ & $\mathrm{N} / \mathrm{A}$ & & 1.41 & -0.41 & \\
\hline \multirow[t]{3}{*}{ Connecticut } & $C E_{A}$ & $0.80(5)$ & $0.81(3)$ & $1.00(1)$ & $0.96(2)$ & $0.78(2)$ & $0.97(4)$ & $0.90(2)$ \\
\hline & $C E_{B}$ & & $0.81(3)$ & $1.20(1)$ & $0.96(2)$ & $0.78(2)$ & $1.15(4)$ & $0.90(2)$ \\
\hline & SCIE & & 6.46 & -5.46 & & 2.40 & -0.40 & \\
\hline \multirow[t]{3}{*}{ New Hampshire } & $C E_{A}$ & $0.51(6)$ & $0.42(8)$ & $0.87(6)$ & $0.44(7)$ & $0.58(6)$ & $0.97(3)$ & $0.67(6)$ \\
\hline & $C E_{B}$ & & $0.42(8)$ & $1.04(6)$ & $0.44(7)$ & $0.58(6)$ & $1.15(3)$ & $0.67(6)$ \\
\hline & SCIE & & 1.05 & -0.05 & & 1.35 & -0.35 & \\
\hline \multirow[t]{3}{*}{ California } & $C E_{A}$ & $0.15(27)$ & $0.11(45)$ & $0.69(13)$ & $0.09(45)$ & $0.11(45)$ & $0.74(14)$ & $0.10(45)$ \\
\hline & $C E_{B}$ & & $0.11(45)$ & $0.82(13)$ & $0.09(45)$ & $0.11(45)$ & $0.88(14)$ & $0.10(45)$ \\
\hline & $S C I E$ & & 0.92 & 0.08 & & 0.95 & 0.05 & \\
\hline \multirow[t]{3}{*}{ Vermont } & $C E_{A}$ & $0.38(8)$ & $0.44(7)$ & $0.96(2)$ & $0.50(6)$ & $0.56(8)$ & $1.00(1)$ & $0.66(7)$ \\
\hline & $C E_{B}$ & & $0.44(7)$ & $1.15(2)$ & $0.50(6)$ & $0.56(8)$ & $1.18(1)$ & $0.66(7)$ \\
\hline & SCIE & & 1.20 & -0.20 & & 1.40 & -0.40 & \\
\hline \multirow[t]{3}{*}{ Texas } & $C E_{A}$ & $0.05(46)$ & $0.05(46)$ & $0.66(19)$ & $0.04(46)$ & $0.07(46)$ & $0.73(19)$ & $0.06(46)$ \\
\hline & $C E_{B}$ & & $0.05(46)$ & $0.80(19)$ & & $0.07(46)$ & $0.86(19)$ & $0.06(46)$ \\
\hline & SCIE & & 0.93 & 0.07 & & 0.95 & 0.05 & \\
\hline
\end{tabular}

Note: Rankings are in parentheses where the rankings are in descending order.

\section{Concluding Remarks}

We have extended the non-spatial CSS efficiency estimator to the case where there is spatial autoregressive dependence. A more detailed empirical application of our estimator covering asymmetric efficiency spillovers would be a worthwhile area for further work.

\section{Acknowledgments}

We thank the Editor, Badi Baltagi, and two anonymous referees for comments and suggestions. The application to state manufacturing was inspired by the participants in the special session dedicated to the memory of Catherine Morrison Paul at the 2012 North American Productivity Workshop.

Baltagi, B. H. (2011). Spatial panels. In A. Ullah, \& D. E. A. Giles (Eds.), Handbook of Empirical Economics and Finance. Boca Raton, Florida: Chapman and Hall, Taylor and Francis Group.

Baltagi, B. H. (2013). Econometric Analysis of Panel Data. 5th Edition. Chichester, UK: Wiley. 
Ciccone, A., \& Hall, R. E. (1996). Productivity and the density of economic activity. American Economic Review, 86, 54-70.

Cornwell, C., Schmidt, P., \& Sickles, R. C. (1990). Production frontiers with cross-sectional and time-series variation. Journal of Econometrics, $46,185-200$.

Druska, V., \& Horrace, W. (2004). Generalized moments estimator for spatial panel data: Indonesian rice farming. American Journal of Agricultural Economics, 86, 185-198.

Glass, A., Kenjegalieva, K., \& Paez-Farrell, J. (2013). Productivity growth decomposition using a spatial autoregressive frontier model. Economics Letters, 119, 291-295.

Hall, B. (2005). Measuring the returns to R\&D: The depreciation problem. Annales d'Économie et de Statistique, 79/80, 341-381.

Lee, L.-F., \& Yu, J. (2010). Estimation of spatial autoregressive panel data models with fixed effects. Journal of Econometrics, 154, 165-185.

LeSage, J., \& Pace, R. K. (2009). Introduction to Spatial Econometrics. Boca Raton, Florida: CRC Press, Taylor and Francis Group.

Morrison, C. J., \& Schwartz, A. E. (1996). State infrastructure and productive performance. American Economic Review, 86, 1095-1111.

Neyman, J., \& Scott, E. L. (1948). Consistent estimates based on partially consistent observations. Econometrica, 16, 1-32.

Schmidt, P., \& Sickles, R. C. (1984). Production frontiers and panel data. Journal of Business and Economic Statistics, 2, 367-374. 